\title{
Gesondheidsdienste en Verantwoordelikhede Onder die nuwe Wet van 1977
}

\author{
J. Gilliland, M.B., B.Ch., M. Med., D.v.G. \\ Departement van Gesondheid
}

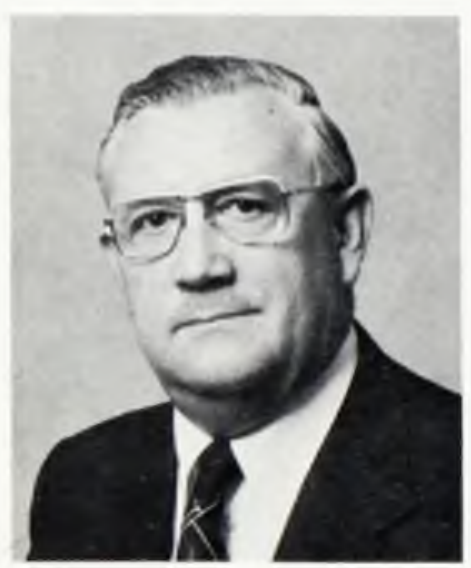

\section{HEALTH SERVICES AND RESPONSIBILITY UNDER THE NEW HEALTH ACT SUMMARY}

A brief hist orical sequence of events leading to the promulgation of the Health Act of 1977 is described. The philosophy of the new Act is discussed stressing the flexibility of health services by the three levels of Government. The policy of consultative policy-making and coordinated decentralised execution is discussed and an outline given of possible responsibilities.

D ie inwerktreding van Hoofstukke I, II en VI van die Wet op Gesond heid, 1977, Wet No. 63 van 1977, op 1 September 1977, het 'n nuwe era ingelui ten opsigte van gesondheidsdienste in die R.S.A.

Met Unie-wording in 1910 het die lede van die Nasionale Konvensie dit blykbaar nie nodig geag om 'n Departement van Gesondheid in te stel nie.

Daar was wel voorsiening gemaak dat die "Kolonies" sou voortgaan met die lewering van dienste in algemene hospitale en liefdadigheidsinrigtings.

Dit was eers nege jaar later nadat die land geteister was deur die 1918 griep-pandemie dat oorgegaan was tot wetgewing.

Gesondheidsdienste in die Republiek van Suid-Afrika was dus lank gelewer in die tradisie en ingevolge die Volksgesondheidswet van 1919. Soos reeds vermeld het hierdie Wet ' $n$ Krisis benodig om op die Wetboek geplaas te word en kan vir die ontstaan van die 3-ledige stelsel van gesondheids- dienslewering verantwoordelik gehou word.

Dit is ook begryplik as ' $n$ mens dink aan die geweldige mortaliteit van die griep-pandemie voor die dae van antibiotika, dat die 1919 wetgewers hulle meerendeels bepaal het tot die bekamping van aansteeklike siektes, die funksies van die plaaslike owerhede en die nuutgestigde sentrale Departement van Gesondheid.

Daar bestaan min twyfel dat die tempo van ontwikkeling, verandering en vooruitgang in die wereld vandag geweldige eise stel op elke faset van ons samelewing. Die ontwikkeling van die mens kan inderdaad beskryf word as die som-totaal van die prosesse waarby hy hom aanpas by die vereistes van sy gedurige veranderlike omgewing.

In die bree veld van gesondheidsdienste word die uitdaging gedurig aan ons gestel om aan te pas by die verreikende en vinnige veranderinge van ons ongewing, om tred te hou met die geweldige tempo van vordering op die gebied van die 
wetenskap en tegnologie. En ontwikkeling moet deurgaans geskied teen die agtergrond van verstedeliking en toenemende industriele ontwikkeling wat gepaard gaan met snelle bevolkingsaanwasse en dreigende energiekrisisse.

Ons word verder uitgedaag ten opsigte van die kwaliteit van menslike bestaan in terme van fisiese, geestelike en sosiale welsyn, wat ook toenemend aangetas word deur bogemelde faktore.

Daar moet gewaak word daarteen dat gekoesterde verwagtinge nie doelmatig kan bevredig word nie ten opsigte van behuising, onderwys, werksmoontlikhede en lone. gesondheids- en welsynsdienste.

Ek het reeds gemeld dat dit 'n krisistoestand was wat aanleiding gegee het tot die totstandkoming van Suid-Afrika se eerste gesondheidswet.

Dit is dus nie verbasend dat die Wet op 21 geleenthede gewysig en aangevul moes word gedurende die afgelope 60 jaar nie. Elke keer was sterk vertoe gerig om basiese veranderinge aan te bring juis omdat dit ' $n$ Wet is wat uit nood en ramp gebore is.

In sy pogings om veranderings in die beginsels van die Wet aan te bring, het die Staat sedert 1924 agt Kommissies, Komitees en Gekose Komitees aangestel om die onderwerp te ondersoek en daaroor aanbevelings te maak. Tot en met 1976 was alle vorige pogings minder geslaagd of selfs tevergeefs, wat hoofsaaklik daaraan toegeskryf kan word, dat daar nie voorheen in geslaag kon word om die verskillende standpunte met mekaar te versoen nie.

Die Vos-Komitee, wat op 15 Oktober 1924 aangestel was om ondersoek in te stel na sekere aspekte van gesondheidsdienslewering, het as volg verslag gedoen:

\begin{abstract}
"Services in the Union, and the relationship between the Union Government, the Provincial Administrations and the Local Authorities inevitably lead to extravagance. The Union Government is directly responsible for some diseases and the Provincial Administrations are responsible for general diseases, while Local Authorities, where such exist, are responsible for some diseases and also share responsibility in certain other cases.

This state of affairs is unsatisfactory and your Committee is convinced that no good purpose will be served by leaving the Provincial Administrations in control of hospitals, when the Union Government through its subsidies to the provinces, contributes by far the larger share of the actual cost. It is clear to your Committee that the only method of dealing properly with the institutional treatment of the sick (excluding mental) is to co-ordinate, under one control, all services of this nature performed by various public bodies.",
\end{abstract}

Dit was ' $\mathrm{n}$ bevinding 54 jaar gelede. Sedertdien het, soos die Schumann-Kommissie dit in sy verslag in 1964 uitgedruk het, "Die versuim van optrede in verband met die VosKomitee se verslag die drie vernaamste groepe van owerhede wat gesondheids- en hospitaaldienste beheer het, vry gelaat om die dienste te ontwikkel sover fondse dit toegelaat het, en grootliks sonder oorlegpleging met mekaar.'

In 1924 is dus reeds gevoel dat omstandighede sodanig verander het, dat veranderings aangebring moes word. In ons huidige opset, met ons geweldige behoeftes aan opgeleide mannekrag en met die aansienlike koste verbonde aan die lewering van gesondheidsdienste, is dit vandag nog te meer so.

Ons land se vermoens aan opgeleide gesondheidspersoneel en finansies kan dit nie bekostig dat hierdie hulpbronne nie maksimaal in 'n gekoordineerde poging aangewend word nie.

Gedurende 1972 is daar 'n begin gemaak met die voorbereiding van 'n nuwe Gesondheidswet. Na die eerste lesing is die Wetsontwerp verwys na 'n Gekose Komitee wat later omskep is na 'n Kommissie van Ondersoek.

Die Kommissie het bevind dat dit duidelik aangewese was dat 'n stelsel met sentrale beleidsbepaling en koördinering en met uitvoering van dienste op "n gedesentraliseerde grondslag moet ontwerp word.

Binne die raamwerk kan die optimum benutting van fasiliteite en mannekrag bewerkstellig word en kan daar rekening gehou word met die eiesoortige behoeftes van die heterogene bevolking. Daar was gepoog om hierdie filosofie in die wetsontwerp in te bou.

Deur wetgewing is dus 'n bloudruk daargestel vir dic lewering van omvattende gesondheidsdienste deur die drie owerheidsvlakke in Suid-Afrika en wat die verwante funksies tussen hulle koordineer.

In plek van die huidige enge bepalings van gesondheidswetgewing word 'n meer buigsame patroon daargestel waarin die bevoegdhede, werksaamhede en pligte van die verskillende owerhede weerspieel word. Voorsiening word ook gemaak vir die koordinasie van dienste en die daarstelling van gesondheidsbeleid op 'n nasionale vlak sodat die funksies en pligte van die verskillende gesondheidsowerhede aangepas word om beskikbare bronne maksimaal te benut en sodoende die beste gesondheidsdiens aan die publiek te bied. Die pogings van die verskillende owerhede kan dus gekoördineer en gerig word om optimum resultate te verkry.

$\mathrm{U}$ sal met my saamstem dat in die tydperk tussen die twee wette ons ingrypende veranderinge in die gesondheidsveld beleef het. In hierdie halfeeu het die mediese wetenskap met rasse skrede vooruitgegaan. Ons het die era van antibiotika en entstowwe betree sodat aansteeklike siektes ' $n$ minder belangrike rol vandag speel en selfs uitgewis word.

Die beheer van endokriene siektes is steeds meer suksesvol en ons toenemende kennis van sellulêre biogemie lei tot die ontwikkeling van nog meer potente middels.

Die geweldige veld wat moderne sjirurgie met sukses dek. het ' $n$ verandering in ons konsep van rehabilitasie van die pasiënt tot gevolg gehad.

Die psigotropiese middels tot ons beskikking vandag, het dit moontlik gemaak dat die psigiatriese pasiënt in die gemeenskap kan behandel word waar hy sy plek kan inneem as 'n nuttige burger. Soortgelyk word buite-pasiëntebehandeling vandag algemeen erken as die beste metode van behandeling van tuberkulose.

Oor die hele wêreld het daar ook gedurende hierdie tydperk 'n merkwaardige klemverskuiwing in die gesondheidsveld plaasgevind. Die vorige aksentuering van groot hospitale en bloot kuratiewe dienslewering het verskuif na premêre gesondheidsorg in 'n gesonde omgewing.

Die nuwe Wet op Gesondheid het beslis voorsiening gemaak vir hierdie nuwe veranderinge en sal ook veroorsaak dat die rol van die multidissiplinêre gesondheidspan moet uitbrei en aanpas om omvattende dienste te lewer.

Dit sal ook lei tot groter gemeenskapsbetrokkenheid met benutting van eie middele. Die belangrikheid van omgewingsgesondheidsdienste in gemeenskapsverband is ' $n$ 
logiese uitwerking. Vir die eerste keer word daar nou ook in wetgewing voorsiening gemaak vir die nodige skakeling tussen al die owerhede vir die beplanning van omvattende gesondheidsdienste.

Daar is "n Gesondheidsake Adviserende Komitee ingestel. bestaande uit verteenwoordigers van die dienslewerende instansies, naamlik amptenare van die Departement van Gesondheid. die Departemente van Hospitaaldienste van die Provinsies, Stedelike en Landelike Plaaslike Besture, en die Departement van Verdediging. Die werksaamhede van die komitee bestaan daaruit om enige aangeleentheid in verband met die gesondheidsdienste van die drie vlakke van gesondheidsowerhede te ondersoek, oorweeg en daaroor aanbevelings by die Minister van Gesondheid vir oorweging deur die Nasionale Gesondheidsbeleidsraad te doen.

Die Komitee word in die verrigting van sy pligte bygestaan deur desk undige subkomitees. Voorsiening is gemaak vir die verpligte aanstelling deur die komitee van afsonderlike subkomitees oor personeel-, tandheelkundige en farmaseutiese aangeleenthede, asook aangeleenthede betreffende geboue vir gesondheidsdienste.

Bogemelde komitees is reeds gekonstitueer en het met hulle werksaamhede begin gedurende November 1977

Bo en behalwe hierdie statutere komitees is verdere komitees ook aangestel deur die Minister van Gesondheid en het ook reeds begin funksioneer.

As gelet word na die verskeidenheid van gesondheidsfunksies wat deur die komitees gedek word, kan die omvang van die werksaamhede besef word.

So is komitees in werking ten opsigte van Psigiatrie. Verpleegdienste. Laboratoriumdienste, Strategiese Kerndata. Gerontologie. Gesondheidsvoorligting, Gesinsbeplanning. Gesondheidsdienste tydens Ramptoestande, Gemeenskapsbetrokkenheid by plaaslike gesondheid, Gesondheidsdienste vir Stedelike Swart Mense. Bo en behalwe hierdie staande komitees is werkskomitees ook tans besig met Distriksgeneesheerdienste. Ambulansdienste en Kindergesondheid.

Daar is dus $n$ bedeling waarby deskundige kennis aan die Advieskomitce beskikbaar gestel word en wat die komitee ook kan adviseer oor plaaslike- en streeksbehoeftes. Die Gesondheids-Adviserende Komitee, bestaande uit persone op die uitvoerende vlak van dienslewerende owerhede, word dus in staat gestel om deskundige kennis te benut ten einde die Gesondheidbeleidsraad te adviseer.

Die Gesondheidsbeleidsraad hestaan uit die Minister van Gesondheid en daardie lede van die Uitvoerende Komitees van dic Provinsiale Rade wat met hospitaaldienste belas is. met die Sekretaris van Gesondheid. wat as Sekretaris optree. Voordat enige aanbeveling deur die Raad oorweeg word, moet die Komitee sodanige aanbevelings aan die Administrateurs vall die provinsies voorlê vir oorweging deur die Uitvoerende Komitees. Die Minister neem die finale besluit. na oorweging deur die Raad. oor enige aanbeveling wat deur die Komitee gedoen is. In die praktyk sal die Minister na goeddunke. enige aangelecntheid waaroor hy "n geskil van mening het met die ander lede van die Raad of waroor hy mel 'n minderheid van die lede van die Raad saamstem. waarskynlik na die Kabinet verwys vir finale beslissing.

Hierdie prosedure stel $n$ bedeling daar waarin deskundige kennis beskikbaar gestel word deur subkomitees wat ten volle op hoogte is van besondere gesondheidsbehoeftes. Alle aangeleenthede wat deur deskundiges ondersoek word. kan dan op ' $n$ bestuursvlak oorweeg word waar al die deelnemers in gesondheidsdienste verteenwoordig word

Die Wet is dus nie rigied of dogmaties nie - inteendeel dit maak voorsiening vir deurlopende en voortdurende evalueering en aanpassing van funksies en verantwoordelikhede

Alhoewel die Provinsiale Administrasies nou vir die eerste keer ' $n$ uitgesproke mandaat gegee word om deel te neem aan die lewering van omvattende gemeenskapsgesondheidsdienste - wat vanselfsprekend voorkomende dienste insluit - sal die siek indiwidu, algemeen gesproke. die besondere verantwoordelikheid van die provinsies word wie die verantwoordelikheid vir kuratiewe persoonlike gesondheidsdienste sal aanvaar.

Maar dit is ook duidelik dat die funksies en verantwoordelikhede van die Provinsiale Administrasies ten opsigte van omvattende dienste in die gemeenskap gaan uitbrei.

Verder word voorsiening gemaak vir die koördinasie van sodanige dienste wat deur "n provinsie gelewer word met dienste wat deur die Departement van Gesondheid of plaaslike besture of naburige provinsies gelewer word

Die funksies van die Provinsies word in Artikel 16 uiteengesit:

(a) om hospitaalfasiliteite en -dienste te verskaf;

(b) om ambulansdienste binne sy provinsie te verskaf en om. met inagneming van soortgelyke dienste wat deur provinsiale administrasies in aangrensende provinsies verskaf word, sodanige dienste te koördineer;

(c) om fasiliteite vir die behandeling van pasiënte wat aan akute geestesongesteldheid ly, te verskaf;

(d) om fasiliteite te verskaf vir die behandeling van buitepasiënte in hospitale of in ander plekke waar pasiënte vir "n tydperk van minder as vier-en-twintig uur behandel word:

(e) om kraaminrigtings en -dienste te voorsien en in stand te hou:

(f) om persoonlike gesondheidsdienste te verskaf, of op sy eie. of in die uitvoering van 'n beslissing geneem deur die Minister ingevolge Artikel 13, in samewerking met 'n plaaslike bestuur;

(g) om die dienste bedoel in paragrawe (a) tot en met (f) met inagneming van soortgelyke dienste wat deur die Departement van Gesondheid, ander provinsiale administrasies en deur plaaslike besture gelewer word, te koördineer met die oog op die daarstelling van 'n omvattende gesondheidsdiens in sy provinsie; en

(h) om enige ander werksaamheid te verrig wat, uit hoofde van 'n beslissing deur die Minister ingevolge Artikel 13 geneem, aan hom toegewys word.

$\mathrm{Ek}$ is seker dat u sal saamstem dat sommige plaaslike owerhede oor die jare heen 'n gesofistikeerde kuratiewe diens gelewer het aan die inwoners in hulle distrik.

As die betrokke provinsies sou besluit dat sodanige plaaslike besture moet voortgaan om hierdie dienste te lewer, kan die provinsie sodanig ooreenkom met die plaaslike besture.

Met die toepassing van hierdie maatreëls is dit moontlik om ons kuratiewe gesondheidsdienste doelmatig te beplan, en om die duplikasie van fasiliteite wat op die grense van provinsies sowel as die wat deur plaaslike besture ingestel is, te verhoed.

Voorkomende en bevorderende gesondheidsdienste het as primêre teiken die persoon wie gesond is of wie se gesond- 
heid in stand gehou of verbeter moet word. Dit is op hierdie vlak waar plaaslike besture onder die nuwe wet hoofsaaklik belas word met die verskaffing en lewering van niepersoonlike gesondheidsdienste. Hierbenewens sal plaaslike besture ook verplig wees om "n voorkomende, bevorderende en gemeenskapsrehabiliterende gesondheidsdiens te lewer. Wat gemeenskapsrehabiliterende dienste betref, is dit die plaaslike bestuur se plig om te verseker dat die pasiënt. nadat hy met behulp van die kuratiewe dienste van 'n siekte herstel het, daarna binne dic gemeenskap gerehabiliteer word.

Rehabilitasie moet hier in sy moderne konsep gesien word: naamlik as die terugkeer na die familie-eenheid en die gemeenskaplewe sowel as integrasie in die ekonomiese ahtiwiteite ten spyte van moontlike fisiese of psigiese gebreke. Daar bestaan geen twyfel dat die rehabilitasie van die persoon wat van 'n geestes- of organiese siekte herstel, hoofsaaklik 'n gemeenskapsverantwoordelikheid is. en dat alles in ons vermoë gedoen moet word om deelname deur die gemeenskap aan te moedig. Onder die nuwe wet is dit moontlik om dit te doen. Voorsiening is ook daarvoor gemaak dat twee of meer plaaslike besture hulle kragte kan saamsnoer en saamwerk om hulle bevoegdhede en hulle werksaamhede in in gesamentlike aksie uit te oefen en te verrig. Sodoende is daar in geleentheid veral vir die kleiner plaaslike besture geskep om "n omvattender diens aan hulle inwoners te lewer.

Die funksies van plaaslike besture word in Artikel 20 uiteengesit:

(a) om sy distrik te alle tye in "n higiëniese en skoon toestand te hou:

(b) om die ontstaan binne sy distrik te voorkom van -

(i) enige oorlas;

(ii) enige onhigiëniese toestand:

(iii) enige aanstootlike toestand; of

(iv) enige ander toestand wat vir die gesondheid van enigiemand binne sy distrik of die distrik van ' $n$ ander plaaslike bestuur skadelik of gevaarlik sal of kan wees, uit die weg te ruim.

(c) om die besoedeling te voorkom van water wat bestem is vir die gebruik van die inwoners van sy distrik. ongeag of sodanige water verkry word van bronne binne of buite sy distrik, of om sodanige water wat aldus besoedel geraak het, te suiwer;

(d) om behoudens die bepalings van hierdie Wet of enige ander Wet, in sy distrik deur die Minister goedgekeurde dienste te lewer vir -

(i) die voorkoming van oordraagbare siektes;

(ii) die bevordering van die gesondheid van persone;

(iii) die rehabilitasie in die gemeenskap van persone wat van ' $n$ mediese toestand genees is,

en om sodanige dienste te koordineer met inagneming van soortgelyke dienste wat gelewer word deur die Departement van Gesondheid of die Provinsiale Administrasie van die provinsie waarin sy distrik geleë is.

Dit moet weer beklemtoon word dat die kompleksiteit van 'n moderne gesondheidsdiens genoodsaak dat daar deurgaans die uiterste buigbarheid en samewerking moet bestaan, nie alleen tussen die betrokke owerhede nie. maar ook tussen die private en openbare sektor, terwyl daar gedurend gewaak word teen onnodige duplikasie.

Die funksies van die Departement van Gesondheid wat omvattend is kan aan die Provinsiale Administrasie gedelegeer word. met uitsondering van Subartikel 14 (i) (a)
Waarin daar dan die Departement opgedra word om die dienste van die verskillende owerhede te koördineer ten einde "n omvattende gesondheidsdiens in die R.S.A. tot stand te bring. Indien die Minister verder cortuig is dat "n plataslike bestuur in stat is om die werksambede te verrig. han dit aan hom opgedra word. Soortgelyk kan die Minister op versoek van 'n plaaslike bestuur, sulke pligte oordrit.

Onder Subartikel 16(f) kan provinsiale administrasies dienste lewer in samewerking met 'n plaaslike bestuur.

Dit is belangrik dat daar by die interpretasic van "persoonlike gesondheidsdienste" na dic definisic van die term in dic Wet gekyk word, naamlik "'n gesondheidsdiens wat gerig is op die ondersoek en behandeling van 'n mediese toestand." As ons dan kyk na die detïnisie van 'n "mediese toestand" word dit omskryt as "n fisiese of psigiese toestand waarin iemand verkeer en wat van so "n toestand is dat dit mediese aandag vereis

Dit is dus duidelik dat die term "persoonlike gesondheidsdiens" hier "n spesiale betekenis het. naamlik die behandeling van persone met siektes, gebreke of afwykings en dat voorkomende en bevorderende gesondheidsdienste nie hierby uitgesluit is nie.

Daar word ook baie duidelik gestel dat die plig van "n plaaslike bestuur is om "enige toestand wat vir die gesondheid van enigiemand binne sy distrik skadelik of gevaarlik sal of kan wees" reg te stel. Hierdic opdrag aan die plaaslike owerheid kan dus slegs dui op optrede om die persoon te beskerm deur optrede soos immuniserings en die algemene verhoging van sy weerstand. Daar kan dus geen twyfel wees dat die immunisering van 'n gesonde persoon wat aan geen mediese toestand ly nie, 'n primêre plig van plaaslike owerhede is nie, al is dit 'n "persoonsgerigte diens."

Dit moet weer beklemtoon word dat die dienste wat deur die verskillende Owerhede gelewer word ten nouste moet gekoördineer word ten einde gesamentlik $n$ omvattende gesondheidsdiens vir die land daar te stel en oorvleueling te voorkom.

Die uitwerking van die Wet sal beslis " $\mathrm{k}$ kemverskuiwing bewerkstellig vanaf ' $n$ bloot kuratiewe benadering na een wat erkenning gee aan voorkomende en bevorderende aspekte wat beehoorlik beplan en uitgevoer word

Hierbenewens is dit ook belangrik dat daar onder alle seksies van die bevolking 'n bewustheid moet ontwikkel ten opsigte van "n breë en omvattende konsep van gesondheid met inagneming ten alle tye van nie-persoonlike gesondheidsdienste.

Die nuwe Gesondheidswet malak dit moontlik vir die daarstelling van 'n omvattende gesondheidsdiens vir SuidAfrika. tot voordeel van die hele bevolking

\section{BIBIIOCFRAIF}

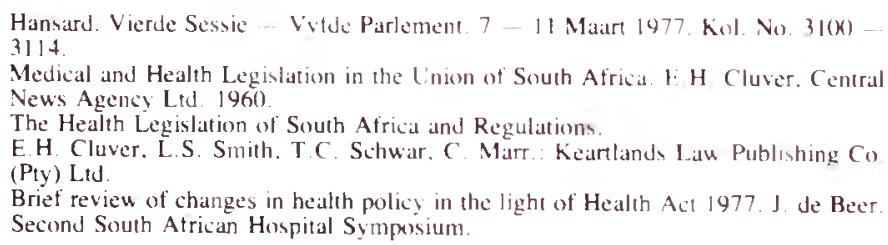

